\title{
INTRODUCCIÓN: LAS CIENCIAS DE LA MENTE Y LA HISTORIA DE LA SUBJETIVIDAD
}

\author{
Enric J. Novella \\ Université du Luxembourg \\ enric.novella@uni.lu
}

Recibido: 15 diciembre 2012; Aceptado: 16 de mayo 2013.

Cómo citar este artículo/Citation: Novella, Enric J. (2013), "Introducción: las ciencias de la mente y la historia de la subjetividad”, Asclepio 65 (2): p012. doi: http://dx.doi.org/10.3989/asclepio.2013.33

\section{INTRODUCTION: THE MIND SCIENCES AND THE HISTORY OF SUBJECTIVITY}

Copyright: (c) 2013 CSIC. Este es un artículo de acceso abierto distribuido bajo los términos de la licencia Creative Commons Attribution-Non Commercial (by-nc) Spain 3.0.

\begin{abstract}
"Estaba, en cuanto a mi mente, morbosamente desarrollado, como corresponde a un hombre de nuestro tiempo"
\end{abstract}
Fiódor Dostoyevski, Apuntes del subsuelo (1864)

En términos generales, no cabe duda de que el notable impulso experimentado por la historia de la ciencia a lo largo del siglo XX constituye un correlato directo de una amplia y creciente conciencia de la propia historicidad de la actividad científica (Rheinberger, 2007). Así, y en estrecha relación con una progresiva consideración de los aspectos materiales, sociales y culturales implicados en la producción del conocimiento científico, la reciente historia de la ciencia ha cuestionado antes que nada la tradicional (e ingenua) creencia inductivista según la cual la ciencia se ocupa de hechos que - por así decirlo- le vienen dados o la preceden, subrayando, por el contrario, la intervención activa de los científicos en la misma construcción del dominio empírico que se proponen esclarecer. En este sentido, Bruno Latour y Steve Woolgar concluían su célebre estudio sobre $L a$ vida en el laboratorio afirmando expresamente que "la actividad científica no versa 'sobre la naturaleza', sino que es una dura lucha por construir realidad" (Latour \& Woolgar, 1979, p. 243).

Estas apreciaciones resultan particularmente pertinentes en el caso de las Ilamadas ciencias de la mente (psicología, psiquiatría y psicoanálisis), cuyo controvertido estatuto epistemológico y cuya abrumadora presencia cultural han animado durante décadas una riquísima y boyante historiografía entre la que descuellan algunos clásicos indiscutibles de las ciencias humanas de nuestro tiempo. A estas alturas, pues, resulta una obviedad sugerir que la naturaleza esencialmente elusiva de todo este campo de conocimiento (Canguilhem, 1968) ha permitido consolidar una aguda percepción de la radical historicidad no solo de sus diversos discursos y prácticas, sino incluso de su mismo objeto de estudio (Jüttemann, 1986; Staeuble, 1991). Las disciplinas de lo mental, en síntesis, son ciertamente el producto histórico y contingente de un largo y complejo proceso de naturalización y secularización del alma o la conciencia (Chadwick, 1975); o, dicho de otro modo, también la mente - esa mente que, al menos desde el siglo XVIII, estudiamos en sus trastornos, su asiento somático o sus funciones (Porter, 2003) - es, ella misma, el resultado de una determinada manera de ver al ser humano cuya cristalización acompaña al despliegue de la ciencia y la cosmovisión moderna (Tarnas, 2008). 
Entre otras cosas, la asunción más o menos generalizada de estas consideraciones epistemológicas e historiográficas ha conducido a numerosos autores a advertir en las ciencias de la mente un escenario paradigmático de las tensiones y aporías relacionadas con el sujeto como categoría central de la Modernidad. Así, por un lado, su surgimiento, su evolución y su extraordinaria proyección no pueden entenderse sin la conformación histórica de una conciencia o subjetividad 'psicologizada', esto es, de una cultura de la individualidad definida por la reflexividad, la promoción de la interioridad y la adscripción de las claves de la identidad personal al ámbito del psiquismo ${ }^{1}$. Pero, por el otro, con su tradicional énfasis en la determinación de los mecanismos subpersonales de la conducta y la experiencia y en el desenmascaramiento de sus móviles ocultos, las ciencias de la mente también han contribuido de un modo decisivo a señalar las escisiones y fracturas que comprometen la unidad, la autodisposición y la coherencia del sujeto, fomentando así esa conciencia de crisis en torno a él que atraviesa la cultura contemporánea y que, huelga decirlo, se nutre a partes iguales de positivismo y de sospecha (Cruz, 1996; Bürger \& Bürger, 2001). En cualquier caso, la centralidad de estas cuestiones ha generado en los últimos años un claro esfuerzo por emplazar el estudio histórico de las ciencias de la mente en el contexto más amplio de una historia social, cultural e incluso política de la subjetividad. Y, de este modo, los trabajos inspirados por este planteamiento han tratado de analizar no solo el modo en que los desplazamientos sociales y culturales vinculados a la irrupción del mundo moderno han condicionado su formación, su articulación doctrinal o su propia institucionalización como disciplinas científicas, sino también su paulatina implantación como marcos de autocomprensión que mueven a los individuos a verse y a actuar de una determinada manera con respecto a sí mismos².

Aunque el vínculo entre historia y subjetividad fue ya abiertamente problematizado por el materialismo marxista y ha encontrado a lo largo del siglo XX expresiones teóricas tan relevantes como la 'psicogenética' de Norbert Elias o el constructivismo social (Staeuble, 1991), existe un amplio consenso en considerar la obra de Michel Foucault como el punto de partida más definido de la reciente historiografía de la subjetividad, hasta el punto de que algunos autores han llegado a afirmar que Foucault "simplemente, inventó todo este campo de estudio" (Moyn, 2009, p. 315). Si, de una parte, resulta difícil sobreestimar la enorme influencia de las aportaciones del filósofo francés en torno a la arqueología de las ciencias humanas o la genealogía del sujeto moderno - bien como función de ciertas prácticas discursivas, bien como correlato de las nuevas relaciones de poder mediadas por las disciplinas (Han, 2005)-, lo mismo puede decirse de su concepto tardío de las 'tecnologías del yo', del que Foucault se sirvió para es- tudiar diversas prácticas espirituales de la Antigüedad - centradas no tanto en el autoconocimiento como en la 'preocupación' o el 'cuidado de sí - y mostrar así la contingencia de distintos procesos o estrategias de subjetivación (Foucault, 1990)³.

Como es lógico, la alargada sombra de la obra foucaultiana -cuya impronta, por lo demás, ha sido también muy notoria en otros campos afines como las historiografías respectivas de la locura, la sexualidad o el cuerpo- no ha impedido a otros autores abordar la historia de la subjetividad desde presupuestos teóricos muy distintos. Y este es el caso, entre otros, del filósofo canadiense Charles Taylor, para quien las "fuentes del yo" y el despliegue de la interioridad moderna deben entenderse ante todo en el marco de los esfuerzos continuados del ser humano por definir y alcanzar la virtud, esto es, como un correlato necesario en la propia evolución de la conciencia moral (Taylor, 1996, pp. 15-123). Este planteamiento de fondo le conduce a establecer una cronología milenaria para la configuración histórica de la subjetividad moderna en la que sobresalen la contribución seminal del cristianismo - Taylor, como ya hiciera Ortega, atribuye a San Agustín nada menos que la formulación paradigmática de la 'reflexividad radical' que caracteriza al individuo moderno-; las de Descartes y Locke como grandes forjadores de esa razón 'desencarnada' (disengaged) que se postula capaz de objetivar los estados mentales y de asumir una posición de tercera persona ante ellos; y, por último, la de esa insigne estirpe francesa de méditatifs interieurs (Sainte-Beuve) que, arrancando en Montaigne y pasando por La Rochefoucauld y Pascal, viene a confluir, ya en la segunda mitad del siglo XVIII, en las célebres Confesiones de Rousseau y los escritos autobiográficos de Maine de Biran (Bürger \& Bürger, 2001, pp. 29-50, 87-101 y 141-153).

En todo caso, y a pesar del incuestionable mérito de una lectura de largo alcance como la propuesta por Taylor, la íntima relación existente entre la constitución de las ciencias de la mente y el despliegue de la subjetividad moderna puede apreciarse mejor atendiendo a algunas de las implicaciones más sobresalientes de la individualidad contemporánea. Como es sabido, la progresiva singularización de las formas y los estilos de vida suscitada por los cambios económicos y sociales consumados a partir del siglo XVIII trajo consigo una conciencia individualista que, mediada por nuevos patrones de experiencia, conducta y comunicación, alentó los ideales de autonomía y emancipación expresados en las revoluciones políticas de la época, pero también la creciente proyección cultural de una subjetividad paulatinamente despojada de sus atributos espirituales (Wahrman, 2004). Esta centralidad del sujeto o el 'yo' - como se empezaba ya a designarlofue activamente promovida por una creciente escisión entre esfera pública y privada que, por su parte, con- 
dujo a una progresiva inserción de la vida familiar e interpersonal en los cada vez más extensos dominios de la privacidad (McKeon, 2005), mientras se difundían una serie de prácticas relacionadas con la introspección o el registro de estados subjetivos (cartas, diarios íntimos, autobiografías, confesiones, etc.) y la creación literaria y artística empezaba a pivotar alrededor de las vicisitudes de una individualidad desbordante pero atenazada por la experiencia de su propia precariedad (Kundera, 1987). Este es, sin duda, el telón de fondo sobre el que hay que contemplar la eclosión del interés por el conocimiento psicológico en la sociedad europea del tránsito del siglo XVIII al XIX, así como el desarrollo en paralelo de diversas formulaciones teóricas en torno al psiquismo - entre las que destacan el sensualismo/ asociacionismo y el espiritualismo- que, con el tiempo, darían paso al surgimiento y la institucionalización de las propias ciencias de la mente como disciplinas científicas (Goldstein, 2003).

Incluyendo la proliferación y la extraordinaria difusión de doctrinas y prácticas no exentas de cierta heterodoxia como la frenología, el magnetismo animal o el hipnotismo, pocos ámbitos de conocimiento reclamaron a lo largo del siglo XIX una mayor atención cultural que el del 'hombre intelectual y moral', sobre cuyo fundamento somático se fueron acumulando además sucesivas aproximaciones que reemplazaron definitivamente la antigua noción del 'órgano del alma' por la concepción contemporánea del cerebro como asiento de las funciones psíquicas superiores (Hagner, 2008) e incluso como locus primario de la identidad personal (Vidal, 2009). En una época en la que la frontera intelectual entre los productores del conocimiento científico y el público culto era todavía relativamente permeable, el discurso psicológico devino así un campo cuyo cultivo sistemático por una serie de pioneros - formados y socializados en su mayoría como profesionales de la medicina- encontró una amplia resonancia entre unas clases instruidas que empezaban a aprehender y describir su propia conducta y experiencia recurriendo a las categorías proporcionadas por los nuevos saberes de lo mental, y que, en el caso de algunos autores particularmente dotados para la observación interior como los franceses Alfred Maury, Ernest Renan, Hyppolite Taine o Gabriel Tarde, hicieron aportaciones de gran relieve al conocimiento psicológico (Carroy, 2008).

En 1892, esto es, en un momento en el que las ciencias de la mente habían alcanzado ya un cierto grado de institucionalización y el psicoanálisis se aprestaba a entrar en escena, el neurólogo alsaciano Hyppolite Bernheim - cuyas experiencias con la sugestión y el hipnotismo admiraron al propio Sigmund Freud- definía justamente la psicología como "el dominio en el que convergen el médico y el hombre de letras" (citado por Micale, 2004, p. 1). De hecho, el periodo que se extiende aproximadamente entre 1880 y 1940 asistió a una intensa interrelación y fertilización cruzada entre las diversas disciplinas de lo mental y el ámbito de la creación artística y literaria, hasta el punto de que es posible establecer una serie de analogías y paralelismos muy reveladores entre el modernismo estético -al que, no en vano, Ortega ya describió como un 'subjetivismo radical' - y el psicológico: intentos de superación del ideario positivista/naturalista, perspectivismo, relativismo, fragmentación 'vertical' y 'horizontal' del yo, interés por el mundo onírico, instintivo y el psiquismo 'primitivo', autorreferencialidad, egotismo, etc. (Micale, 2004). En este sentido, es interesante señalar que la esquizofrenia, una de las categorías más emblemáticas (y esquivas) de la psiquiatría contemporánea, no solo fue aislada conceptualmente en el tránsito del siglo XIX al XX y tuvo una enorme popularidad en las décadas siguientes, sino que ha sido interpretada por algunos estudios como una suerte de paroxismo aberrante de la reflexividad cuyas manifestaciones psicopatológicas más prominentes remiten de forma invariable a la misma atmósfera cultural que alumbró la literatura de James Joyce, Marcel Proust y Franz Kafka o la pintura de Giorgio de Chirico, René Magritte y Salvador Dalí (Sass, 1992).

Ciertamente, la irrupción del psicoanálisis y la perdurable impronta de su fundador - al que, no en vano, el poeta inglés W. H. Auden llegó a definir como "todo un clima de opinión" - confirieron un nuevo impulso a la proyección del conocimiento psicológico, cuya franca progresión a lo largo del siglo XX ha alcanzado, como bien sabemos, la práctica totalidad de ámbitos relevantes de la vida cotidiana (educación, trabajo, relaciones interpersonales, sexualidad, etc.) y ha derivado en el variopinto conjunto de discursos y prácticas que cohabitan en la 'cultura terapéutica' de nuestros días (Illouz, 2010). Y, en este contexto de consumo masivo de los conceptos y categorías de las ciencias de la mente, de absorción solipsista en los interminables avatares de la 'vida emocional' y de fascinación generalizada por todo tipo de técnicas de autoconocimiento y manipulación del 'yo', parece lógico que las transformaciones históricas de la subjetividad que subyacen y reflejan todos estos desarrollos se hayan convertido en objeto de una creciente atención teórica e historiográfica. En cierto modo, pues, resulta cada vez más evidente que la historia de la ciencia y de nuestra cultura no pueden prescindir de la exploración 'genealógica' de las coordenadas que han posibilitado la formación de las disciplinas psicológicas modernas, pero tampoco pueden obviar el hecho de que, a lo largo de la Modernidad, los distintos saberes de lo mental han condicionado de forma decisiva el modo en que los individuos se conciben y actúan con respecto a sí mismos. La historia de la psicología, la psiquiatría y el psicoanálisis, en definitiva, no pueden prescindir de la historia cultural de la subjetividad, 
pero esta, a su vez, no puede obviar la evolución y la extraordinaria proyección del discurso psicológico en la cultura contemporánea 4 .

De acuerdo con este planteamiento de fondo, el presente dossier de Asclepio reúne un total de cinco artículos originales redactados por un grupo de investigadores de reconocido prestigio que participaron en el congreso internacional 'Mente, sujeto e historia: Ciencia y subjetividad en la cultura contemporánea', celebrado los días 12 y 13 de mayo de 2011 en el Centro de Ciencias Humanas y Sociales del CSIC en Madrid. Contando con una generosa subvención del Ministerio de Ciencia e Innovación dentro de su programa de Acciones Complementarias de Investigación (HAR2010-11150-E/HIST), las sesiones del congreso congregaron a una quincena de especialistas en psicoanálisis, historia de la ciencia y literatura cuyas ponencias abordaron una serie de cuestiones relacionadas con cuatro ejes temáticos principales: (1) los orígenes culturales de los discursos y conceptos de la psicología, la psiquiatría o el psicoanálisis; (2) el papel de la aportación de los no expertos, la cultura popular y las experiencias autobiográficas en la construcción del conocimiento científico en torno a la locura, las emociones, los sueños o la vida instintiva; (3) el impacto y la proyección de las ideas psicológicas, psiquiátricas y psicoanalíticas en la literatura y el arte contemporáneos; y (4) la normatividad de los patrones de reflexividad en las sociedades contemporáneas y la constitución de subjetividades marginales.

A pesar de que no ha sido posible recuperar la totalidad de dichas ponencias, el presente dossier constituye una buena muestra de la extraordinaria amplitud y la necesaria interdisciplinariedad de todo este campo de estudio, en las que las múltiples y constantes afinidades, transferencias e interdependencias entre las historias respectivas de la subjetividad, el conocimiento psicológico/psiquiátrico y la creación literaria se revelan como aspectos entrelazados de una misma constelación cultural. Así lo esboza ejemplarmente Joan Oleza Simó en su artículo sobre la figura del apócrifo como expresión literaria de la crisis de la concepción sustancial y unitaria de la subjetividad heredada de la primera Modernidad; con ese objetivo, y tras una breve revisión histórica de la conformación de la subjetividad moderna, su trabajo ofrece un lúcido análisis del "triple asalto a la idea de sujeto" encarnado por las obras de Marx, Nietzsche y Freud, a la vez que reconstruye la cristalización literaria de la escritura apócrifa en autores tan señalados como Fernando Pessoa, Antonio Machado o Max Aub.

Posteriormente, Anne-Cécile Druet encara la temprana presencia del psicoanálisis en la literatura española con la aparición a finales de la década de 1920 de una serie de obras teatrales y novelas en las que la autora rastrea tanto la representación del psicoanalista y del método freudiano como la función literaria otorgada al psicoanálisis por los autores españoles, entre los que destacan algunos de tanto relieve como los hermanos Machado o Llorenç Villalonga; en este sentido, el trabajo concluye que el psicoanálisis produjo un novedoso énfasis en el análisis de las motivaciones inconscientes de los personajes, y que, aunque no llegara a producir obras tan notables como La coscienza di Zeno (1923) de Italo Svevo, su impacto literario constituye un importante elemento dentro de la recepción general de la obra de Freud en la cultura española. En una órbita similar cabe situar igualmente el estudio de Ángel González de Pablo, que presenta el rico testimonio de la Autobiografía psíquica del novelista austríaco Hermann Broch (1886-1951) como un ejemplo particularmente interesante de la prominencia y la infiltración del psicoanálisis en la cultura psicológica de la primera mitad del siglo XX; así, tras una breve introducción histórica a los grandes procesos e instancias de conformación de la subjetividad moderna, el trabajo muestra la irrupción del psicoanálisis no solo como un cuestionamiento definitivo del sujeto psicológico (consciente) tradicional, sino también como una vía de reconstrucción discursiva de un mundo interno atenazado por la experiencia de su propia precariedad y fragmentación, pero menos constreñido y, por tanto, más libre y versátil con respecto a sus posibilidades de recreación estética y ética.

Por último, y tomando respectivamente como objeto el profundo arraigo del espiritualismo psicológico en la España del siglo XIX y la controvertida contribución de la psiquiatría de entresiglos a la redefinición categorial de subjetividades marginales (locos, criminales y, en suma, 'anormales' de todo tipo y condición) y de diversas estrategias de defensa social, los artículos del firmante de estas líneas y de Ricardo Campos abordan la dimensión ideológica y normativa de las doctrinas psicológicas y psiquiátricas, cuyas formulaciones teóricas resultan difícilmente separables de los intereses que las subyacen y la vocación pragmática que las animan en tanto propuestas - convenientemente avaladas por la supuesta neutralidad y legitimidad del conocimiento científico- de gestión de la individualidad y la diferencia. En cierto modo, pues, sus páginas ofrecen un buen contrapunto con el que concluir este modesto proyecto en torno a un ámbito tan complejo y problemático $-\mathrm{y}$, a la vez, tan constitutivo de nuestro mundo- como la creciente proyección cultural de unos discursos y prácticas que, en definitiva, siempre acaban remitiéndonos a un sujeto en permanente construcción y crisis: nunca suficientemente emancipado, nunca suficientemente integrado. 


\section{NOTAS}

1 Para una visión de conjunto en torno al desarrollo histórico de esta cultura de la subjetividad pueden consultarse Renaut (1993), Taylor (1996), Fetz, Hagenbüchle \& Schulz (1998), Wahrman (2004) o Seigel (2005), así como los trabajos de Joan Oleza y Ángel González de Pablo incluidos en el presente dossier.

2 Entre los trabajos que asumen de un modo u otro esta perspectiva de análisis cabe destacar los de Danziger (1990), Rose (1990), Cushman (1995), Pfister \& Schnog (1997), Rose (1999), Goldstein (2005) o Thomson (2006)

3 Un ejemplo particularmente logrado de aplicación del concepto de 'tecnologías del yo' puede encontrarse en el estudio ya citado de Jan Goldstein sobre la evolución del discurso psicológico en la Francia pre y posrevolucionaria, en el que su autora

\section{BIBLIOGRAFÍA}

Bürger, Meter y Bürger, Christa (2001), La desaparición del sujeto: Una historia de la subjetividad de Montaigne a Blanchot, Madrid, Akal.

Canguilhem, Georges (1968), “Qu'est-ce que la psychologie?". En: Études d'histoire et de philosophie des sciences, París, Vrin, pp. 365-381.

Carroy, Jacqueline (2008), "Observation, expérimentation et clinique de soi: haschich, folie, rêve et hystérie au XIXe siècle". En: Daled, Pierre F. (dir.), L'envers de la raison. Alentour de Canguilhem, París, Vrin, pp. 53-71.

Cruz, Manuel (comp.) (1996), Tiempo de subjetividad, Barcelona, Paidós.

Cushman, Philip (1995), Constructing the Self, Constructing America: A Cultural History of Psychotherapy, Reading MA, Addison-Wesley.

Chadwick, Owen (1975), The Secularization of the European Mind in the Nineteenth Century, Cambridge, Cambridge University Press.

Danziger, Kurt (1990), Constructing the Subject: Historical Origins of Psychological Research, Cambridge, Cambridge University Press.

Fetz, Reto L.; Hagenbüchle, Roland y Schulz, Peter (eds.) (1998), Geschichte und Vorgeschichte der modernen Subjektivität, Berlín, De Gruyter.

Goldstein Jan E (2003), "Bringing the psyche into scientific focus". En: The Cambridge History of Science, Vol. 7: The Modern Social Sciences, Cambridge, Cambridge University Press, pp. 131-153.

Goldstein, Jan E. (2005), The Post-Revolutionary Self: Politics and Psyche in France 1750-1850, Cambridge MA, Harvard University Press.

Hacking, Ian (2001), “Locura: ¿biológica o construida?”. En: ¿La construcción social de qué?, Barcelona, Paidós, pp. 169-205. polemiza - acertadamente, a mi juicio- con la pretensión del propio Foucault de descartar las teorías filosóficas de la mente, las pasiones o el cuerpo como elementos relevantes en la constitución del sujeto (Goldstein, 2005, pp. 13-15). Véase, en este sentido, Novella (2009).

4 Conclusiones similares para la historiografía de la subjetividad se sugieren en un extraordinario artículo de Fernando Vidal (2002), especialmente pp. 971-974, donde se alude expresamente al 'nominalismo dinámico' de lan Hacking y a su concepto de 'clases interactivas' como una propuesta que puede orientar provechosamente futuros estudios sobre el impacto cultural de las ciencias de la mente y las neurociencias. Véase, en este sentido, Hacking (2001).

Hagner, Michael (2008), Homo cerebralis: Der Wandel vom Seelenorgan zum Gehirn, Frankfurt, Suhrkamp.

Han, Béatrice (2005), "The analytic of finitude and the history of subjectivity". En: Gutting, Gary (ed.), The Cambridge Companion to Foucault (2 ${ }^{\mathrm{a}}$ ed.), Nueva York, Cambridge University Press, pp. 176-209.

Illouz, Eva (2010), La salvación del alma moderna. Terapia, emociones y la cultura de la autoayuda, Madrid, Katz.

Jüttemann, Gerd (ed.) (1986), Die Geschichtlichkeit des Seelischen: Der historische Zugang zum Gegenstand der Psychologie, Weinheim, Beltz Verlag.

Kundera, Milan (1987), El arte de la novela, Barcelona, Tusquets.

Latour, Bruno y Woolgar, Steve (1979), Laboratory Life: The Social Construction of Scientific Facts, Londres, Sage.

McKeon, Michael (2005), The Secret History of Domesticity: Public, Private, and the Division of Knowledge, Baltimore MD, The Johns Hopkins University Press, 2005.

Micale, Mark S. (2004), "The modernist mind: a map". En: The Mind of Modernism. Medicine, Psychology, and the Cultural Arts in Europe and America, Stanford, Stanford University Press, pp. 1-19.

Moyn, Samuel (2009), "The assumption by man of his original fracturing: Marcel Gauchet, Gladys Swain, and the history of the self", Modern Intellectual History, 6, pp. 315-341.

Novella, Enric J. (2009), "De la historia de la psiquiatría a la historia de la subjetividad", Asclepio. Revista de Historia de la Medicina y de la Ciencia, LXI(2), pp. 261-280.

Pfister, Joel y Schnog, Nancy (eds.) (1997), Inventing the Psychological: Towards a Cultural History of Emotional Life in America, New Haven, Yale University Press.

Porter, Roy (2003), Flesh in the Age of Reason, Londres, Allen Lane. 
Renaut, Alain (1993), La era del individuo: Contribución a una historia de la subjetividad, Barcelona, Destino.

Rheinberger, Hans-Jörg (2007), Historische Epistemologie zur Einführung, Hamburgo, Junius.

Rose, Nikolas (1990), Governing the Soul: The Shaping of the Private Self, Londres, Routledge.

Rose, Nikolas (1999), Inventing Our Selves: Psychology, Power and Personhood, Cambridge, Cambridge University Press.

Sass, Louis A. (1992), Madness and Modernism: Insanity in the Light of Modern Art, Literature and Thought, Nueva York, Basic Books.

Seigel, Jerrold (2005), The Idea of the Self: Thought and Experience in Western Europe Since the Seventeenth Century, Cambridge, Cambridge University Press.

Staeuble, Irmingard (1991), "Psychological man and human subjectivity in historical perspective", History of the Human Sciences, 4, pp. 417-432.
Tarnas, Richard (2008), La pasión de la mente occidental, Vilaür, Atalanta.

Taylor, Charles (1996), Fuentes del yo: La construcción de la identidad moderna, Barcelona, Paidós.

Thomson, Mathew (2006), Psychological Subjects: Identity, Health and Culture in 20th Century England, Oxford, Oxford University Press.

Vidal, Fernando (2002), "Brains, bodies, selves, and science: Anthropologies of identity and the resurrection of the body", Critical Inquiry, 28, pp. 930-974.

Vidal, Fernando (2009), "Brainhood, antropological figure of modernity", History of Human Sciences, 22 (1), pp. 5-36.

Wahrman, Dror (2004), The Making of the Modern Self: Identity and Culture in Eighteenth-Century England, New Haven, Yale University Press. 